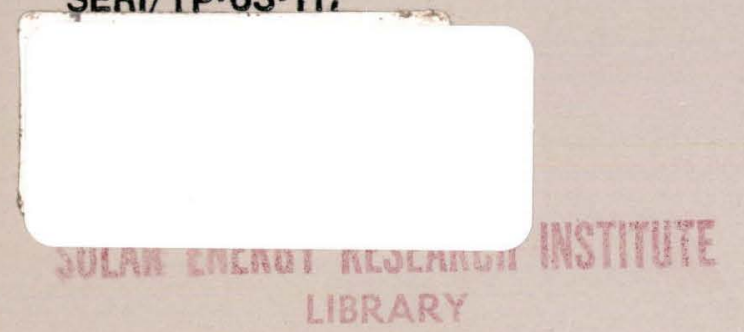

\section{APR 111979}

Golden, Colorado 80401

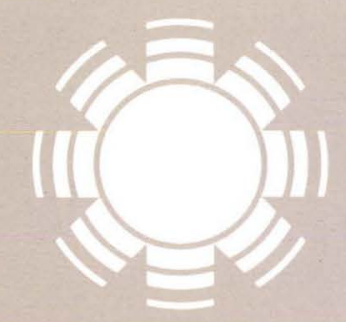

SERI/TP-63-117

c.2
Standards for Passive Solar Heating and Cooling

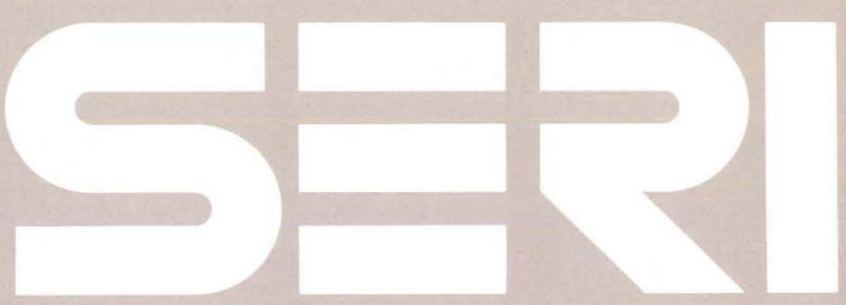

Michael J.Holtz

Solar Energy Research Institute

1536 Cole Boulevard

Golden, Colorado 80401 


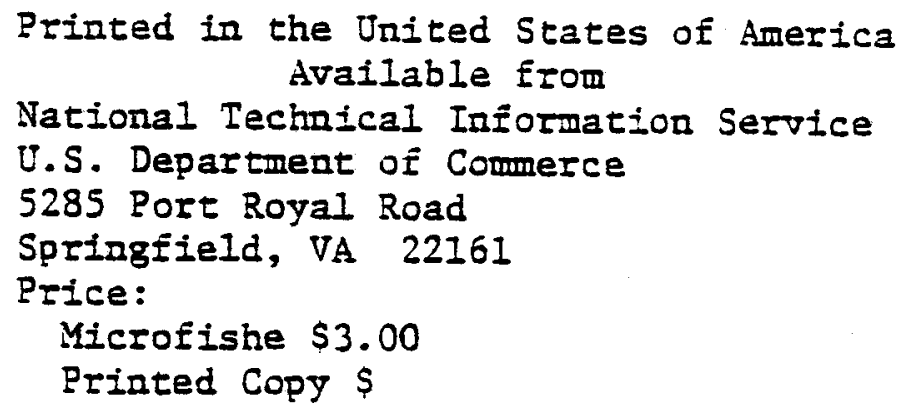

NOTICE

This report was prepared as an account of work sponsored by the United States Government. Neither the United States nor the United States Department of Energy, nor any of their employees, nor any of their contractors, subcontractors, or their employees, makes any warranty, express or implied, or assumes any legal liability or responsibility for the accuracy, completeness or usefulness of any information, apparatus, product or process disclosed, or represents that its use would not infrirge privately owned rights. 
STANDARDS FOR PASSIVE SOLAR HEATING AND COOLING

\author{
MICHAEL J. HOLTZ, R.A., CHIEF \\ PASSIVE TECHNOLOGY BRANCH \\ SOLAR ENERGY RESEARCH INSTITUTE
}

PRESENTED AT THE SECOND NATIONAL CONFERENCE ON STANDARDS FOR SOLAR ENERGY USE, NEW YORK CITY

SEPTEMBER 13, 1978 
There has been a general trend toward accelerating the development of solar standards. Many equate the development of standards with the expeditious growth of the solar industry. Others wisely emphasize that "...standards should follow not lead technology." This statement is particularly appropriate to the current push to develop standards for passive solar heating and cooling. This paper supports the latter view.

\section{DEFINITION OF "PASSIVE": A UNIQUE SOLAR TECHNOLOGY}

Passive systems are defined as those in which the thermal energy flows by natural means (radiation, convection, and conduction). Except for thermosyphon water and air heaters, passive systems are generally integral to the building; the building and the system are one and the same. Passive systems are not in most cases discrete elements that can be separated from the building. In fact, the manner in which the building is designed (the spatial organization and relationship, the selection of materials, placement on the site) has considerable influence on the performance of the passive techniques.

It is important to understand that although the concern here is with natural transfer of energy, the topic in fact is energy-conscious, climate-adaptive, site-specific architecture. This fact poses unique challenges for the development of standards for passive solar systems.

\section{STANDARDS: ADVANTAGES AND DISADVANTAGES}

In light of the preceding definition of passive systems it is useful to review the reasons for developing standards and the reasons for exercising caution in their development and promulgation. The advantages of standards are:

- to protect homeowners, their health, and safety, and investment, and to provide them with reasonable expectations of performance;

- to protect lenders' investments;

- to engender trust and credibility of the industry as a whole; and

- to provide a common language for communication. This is particularly pertinent to the field of passive solar heating and cooling, which has been confused by local and homemade jargon.

An attempt is being made in developing the National Passive Plan to establish a standard language for referring to various types of passive design. The National Plan is being developed jointly by the Department of Energy, the Solar Energy Research Institute, and Lawrence Berkeley Laboratory. 
The dangers inherent in standards development are many, but a few are common. First, the standards development process is by nature and design a slow deliberate activity and the solar industry is in a rush. It generally takes two to four years to perform all the necessary actions in standards promulgation. Even with this amount of time the resulting standards may not reflect the best state of the art or be responsive to a changing technology. A recent example with which people are familiar is the ASHRAE 90-75 building energy conservation standards. It was found by surveying buildings designed during the period of standards development that those buildings often consumed less energy than the standard provisions required. It was a simple case where the standards were behind the state of the art.

Furthermore, HUD is currently looking at the development of mandatory energyefficient standards based on an energy budget (i.e., a particular building type, for a particular occupancy, in a particular climate zone can use a

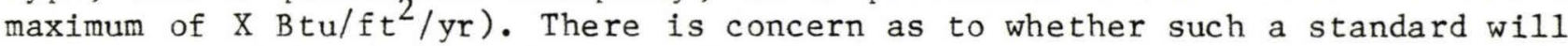
support or detract from the use of solar energy systems in buildings. SERI will be looking at HUD's proposal for Energy Efficient Standards to determine its effect on solar technology.

Second, standards frequently become laws through incorporation into building codes. Occasionally, instead of merely referencing a standard to show compliance with a code provision, standards have become the provision. When this occurs it is very difficult to change either the standard or the code provision.

Third, narrowly phrased prescriptive standards may preclude many viable alternatives. Standards historically represent a snapshot of the state of the art of a particular technology. The challenge to standards development is to write standards that allow the technology to change and improve without excessive constraint.

Fourth, members of standards committees may not be representative of all interested and affected parties. Public interests are at times not adequately represented by committees dominated by industry concerns.

Finally, standards may be used for purposes other than what they were intended. For example, compliance with standards can be used as a prerequisite for market access or government purchases or tax credits. With the recent surge of federal, state, and local solar energy tax legislation this is not a minor issue. 


\section{STATUS OF STANDARDS FOR PASSIVE SYSTEMS}

The Solar Heating and Cooling Demonstration Act of 1974 called for the development of interim and definitive performance criteria so as to ensure the demonstration of effective, reliable, and safe solar heating and cooling systems. The National Bureau of Standards prepared these interim criteria for both residential and commercial buildings with the intent that the criteria would evolve over time based on data from the demonstration program to become the standards for the industry. NBS realized that there must be considerable industry participation in reviewing and evaluating the performance criteria and in developing the numerous criteria upon which the standards would be based. With NBS and DOE support, the American National Standards Institute established the Solar Standards Steering Committee to guide and coordinate all solar standards activity. The committee is made up of representatives from all segments of the industry that would be affected by solar standards and that develop and promulgate standards. NBS prepared a report that identified numerous areas where standards were needed, including passive solar heating and cooling. The coordination role for passive standards development was assigned to the representative from the American Institute of Architects. Some work was done to identify current work related to passive standards and to recommend work that needed to be done. One recommendation that resulted was a need to develop Iong term performance data on the thermophysical properties of glazings in various combinations in different framing assemblies. The Architectural Aluminum Manufacturing Association, through its solar energy committee, prepared a mission statement and was to initiate an activity to develop these data.

ASTM has recently established a standing Solar Energy Committee E44. A subcommittee, E44.14, has been formed to look at the needs for passive standards. Its scope is as follows:

To develop, provide, and publicize, as needed, standard definitions, practices, methods, classifications, and specifications as required to evaluate characteristics and performance of materials, products, components, and systems used in passive solar applications.

The committee has organized itself into the following task groups:
- liaison,
- survey of existing standards and activities,
- performance functions, and
o test procedures.

The committee has met twice and has just begun to identify standards needs for passive technology or existing standards applicable in whole or with modifications to passive solar installations. 
The most recent organization to become involved with passive standards is the Passive Systems Division of the American Section of the International Solar Energy Society. The Passive Systems Division (PSD) passed a motion at the recent AS/ISES meeting in Denver to form a standing Standards Codes Recommendation Committee to "develop a statement of the views of the Passive System Division on standards creation as they relate to the development of passive solar utilization, and that this committee be in communication with the ASTM." The committee will investigate passive standards as they relate to testing procedures, recommended performance levels, and building codes. The investigations are to focus on passive standards on three levels: materials, components, and systems.

The approach to be taken for this activity consists of three tasks: (1) collect, organize, critique, and disseminate information on present standards/codes that are being developed or have been adopted; (2) act as a liaison between the PSD and the various standards and codes organizations or institutions; and (3) investigate certification standards for passive solar tax credits.

\section{RECOMMENDATIONS AND CAUTIONS}

1) The Federal government should not attempt to accelerate standards development in passive solar heating and cooling before a thorough analysis and assessment of existing standards and of potential costs and benefits of the standards to passive solar development and utilization.

2) The private sector, through organizations such as ANSI, ASTM, AIA, and AS/ISES, should pursue programs to analyze thoroughly standards needs for passive technology and to review existing standards for applicability.

3) Implementation procedures of Building Energy Performance Standards should be carefully evaluated so as to not discourage or unintentionally prohibit or limit the use of passive solar heating and cooling techniques.

4) Required for all standards development activities that the government is asked to support should be a standards impact statement to assess the probable costs and benefits of developing and promulgating the standards.

5) Where passive standards needs have been identified and the impacts of standards development are minor, representation by all parties affected must be ensured. 
6) Existing standards and codes should be analyzed to remove or modify present constraints to the use of passive systems.

\section{SUMMARY}

The need for passive system standards has been recommended by some quarters of the building industry, mainly as a result of a concern for equal consideration for proposed solar energy tax credits or property tax exemptions. This reason alone is not sufficient to warrant the development and adoption of standards that may well encumber the utilization and further development of passive systems. Passive designs are architectural responses to climatic conditions for the purposes of saving fuel and providing human comfort. As such, the diversity in design approaches is perhaps beyond the bounds of standards. What may be appropriate would be specific product or assembly material and test standards that would allow comparative evaluation of the same functional element (glazing performance, movable insulation, etc.). It is in this area of materials and assemblies that existing standards need to be evaluated and new standards proposed for passive design techniques. 